\title{
Unsafe driving behaviour and four wheel drive vehicles: observational study
}

Lesley Walker, Jonathan Williams, Konrad Jamrozik

\begin{abstract}
Objective To assess the level of compliance with the new law in the United Kingdom mandating penalties for using a hand held mobile phone while driving, to compare compliance with this law with the one on the use of seat belts, and to compare compliance with these laws between drivers of four wheel drive vehicles and drivers of normal cars.

Design Observational study with two phases-one within the "grace" period, the other starting one week after penalties were imposed on drivers using such telephones.

Setting Three busy sites in London.

Participants Drivers of 38182 normal cars and 2944 four wheel drive vehicles.

Main outcome measures Proportions of drivers seen to be using hand held mobile phones and not using seat belts.

Results Drivers of four wheel drive vehicles were more likely than drivers of other cars to be seen using hand held mobile phones $(8.2 \% v 2.0 \%)$ and not complying with the law on seat belts $(19.5 \% v 15.0 \%)$. Levels of non-compliance with both laws were slightly higher in the penalty phase of observation, and breaking one law was associated with increased likelihood of breaking the other.

Conclusions The level of non-compliance with the law on the use of hand held mobile phones by drivers in London is high, as is non-compliance with the law on seat belts. Drivers of four wheel drive vehicles were four times more likely than drivers of other cars to be seen using hand held mobile phones and slightly more likely not to comply with the law on seat belts.
\end{abstract}

\section{Introduction}

In 1975 Peltzman proposed the theory of "risk compensation," whereby drivers make a trade-off between the probability of having a crash and "driving intensity" (increased speed, less journey time, and more thrills). ${ }^{1}$ Deaths of pedestrians, cyclists, and rear seat passengers increased (by 8\%,13\%, and 28\%, respectively) after laws mandating the use of seat belts in front seats were introduced in the United Kingdom. ${ }^{2}$ It has been argued that these data support Peltzman's theory, as they are consistent with drivers taking more risks when they are required to wear seat belts, and similar predictions have been made about drivers of four wheel drive vehicles. ${ }^{3}$ In 1993 the UK Department of Transport issued 500000 leaflets stating that large cars are safer than small cars, and data from the United States indicate that drivers of sports utility vehicles (which are similar to four wheel drive vehicles) are less likely to be injured in a collision between two vehicles than drivers of normal cars. ${ }^{45}$ In the past decade, several new models of four wheel drive vehicles have become available in the UK. Many of these vehicles never go "off road," but their owners like the high position and the feeling of safety that these vehicles provide for urban driving.

Studies from the UK, US, and Australia provide compelling evidence that using a hand held mobile phone while driving increases the chance of having a crash by up to four times. ${ }^{6-12}$ This fact was well publicised in the UK (including in government publicity campaigns) before drivers were banned from using such telephones on 1 December 2003. The change in the law was followed by a "grace" period of three months, during which police only cautioned offenders. Penalties were imposed on offending drivers from 1 March 2004.

Evidence from countries with similar bans indicated that compliance with the new law in the UK would be incomplete. ${ }^{13-15}$ We investigated whether the new law had been effective, and we used wearing of seat belts as a comparison behaviour. We predicted that compliance with both laws would be lower among drivers of four wheel drive vehicles than drivers of other cars owing to risk compensation.

\section{Methods}

\section{Setting and design}

We conducted an observational study at three different sites in Hammersmith in inner West London. Each site had good visibility of the carriageway. One was on a busy main arterial road, the second was close to three schools, and the third was in a built-up mixed industrial and residential area. One observer recorded the prevailing weather conditions and details of passing motor traffic at each location on Monday to Friday for one hour in the morning (9-10 am), afternoon (1-2 pm), and early evening (4-5 $\mathrm{pm})$. We conducted the first round of 45 sessions of observation over three weeks in February 2004, while the grace period regarding use of mobile phones was still in force. The series of observations was repeated one month later, starting one week after police began to impose penalties for non-compliance with the new law.

\section{Collection of data}

The survey was limited to private passenger vehicles; we excluded taxis, buses, vans, and trucks. We categorised passenger vehicles into cars (defined as vehicles that are not designed to travel off road) and four wheel drive vehicles (we compiled a list of these vehicles by searching the internet for major motor vehicle manufacturers and sales outlets). For each eligible vehicle, the observer recorded its type (four wheel drive or car) and whether the driver was wearing a seat belt or using a hand held mobile phone (or both). The observer also noted if a driver's status could not be discerned, usually because of tinted windows or poor 
Table 1 Prevalence of non-compliance with laws on mobile phones and seat belts in London. Values are number (\%)

\begin{tabular}{|c|c|c|c|c|}
\hline \multirow{2}{*}{ Using mobile telephone } & \multicolumn{2}{|c|}{ Driving four wheel drive vehicle $(n=2944)$} & \multicolumn{2}{|c|}{ Driving normal car ( $\mathrm{n}=38$ 182) } \\
\hline & Wearing seat belt & Not wearing seat belt & Wearing seat belt & Not wearing seat belt \\
\hline No & $2186(74.3)$ & $518(17.6)$ & $31860(83.4)$ & $5547(14.5)$ \\
\hline Yes & $183(6.2)$ & $57(1.9)$ & $604(1.6)$ & $171(0.5)$ \\
\hline
\end{tabular}

Percentages relate to total numbers of relevant type of vehicle.

light. We did not record registration numbers or other details of vehicles or drivers.

\section{Analysis}

We used Stata statistical software (version 7) to analyse the data, $\chi^{2}$ tests to compare crude proportions of drivers of different types of vehicles using mobile phones or not wearing seat belts in the grace and penalty phases, and Poisson regression to adjust for possible confounders and the variables that defined clusters of observations. These variables include location, day of the week, time of observation, and driving conditions (five combinations of lighting and precipitation). We also adjusted for traffic density, measured as the total number of eligible vehicles recorded during the hour of observation, as scatter plots showed that use of a mobile phone and not using seat belts tended to fall as density increased. The analyses do not include data from the pilot phase in which field locations, methods of recording, and duration of the recording session were finalised.

\section{Results}

Over the two phases of recording we counted 41781 eligible vehicles, of which $7.5 \%(n=3121)$ were four wheel drive vehicles. The number of vehicles recorded in an hour varied from 172 to 1110 (mean 464, median 407). Because the roads were busier in the second phase, the overall median density to which observed drivers were exposed was 575 vehicles per hour. The driver's status with regard to mobile phone and seat belt could not be discerned for 478 (1.2\%) normal cars and 177 (5.7\%) four wheel drive vehicles. These instances have been removed from denominators for calculation of non-compliance with laws on seat belts and mobile phones.

Overall, almost one in six drivers $(\mathrm{n}=6293,15.3 \%)$ was not wearing a seat belt and one in $40(\mathrm{n}=1015,2.5 \%)$ was using a hand held mobile phone while he or she passed the observer. Both of these proportions were slightly higher in the penalty phase of observation than during the grace period (noncompliance with seat belt $15.8 \% v 14.8 \%$; use of mobile phone $2.6 \%$ $2.3 \%)$.

Drivers of four wheel drive vehicles were more likely than drivers of other cars to be seen breaking laws on the use of seat belts and hand held mobile phones (table 1). This was consistent across strata defined by site, day, time, and driving conditions. In a multivariate Poisson model adjusting for phase, location, time of day, day of the week, driving conditions, and density of traffic (table 2), drivers of four wheel drive vehicles were almost four times more likely than those of cars to be seen using a mobile phone (incidence rate ratio $3.89,95 \%$ confidence interval 3.36 to 4.49). In an equivalent model for not using seat belts (table $2[t]$ ), drivers of four wheel drive vehicles were $26 \%$ more likely to be non-compliant with the law than drivers of other cars $(1.26,1.16$ to 1.38). Each model showed that breaking one law was significantly associated with increased likelihood of breaking the other. For example, $3.6 \%$ of drivers not wearing seat belts also used a hand held mobile phone (compared with 2.3\% of those wearing a seat belt), and $22.0 \%$ of drivers using a telephone were not wearing a seatbelt (compared with $15.1 \%$ of those not using a mobile phone). Overall, phase (grace or penalty) had only a small effect on both behaviours, and drivers were more likely to wear a seat belt and not to use a mobile phone when the traffic was heavier.

\section{Discussion}

Our data show a worryingly high level of non-compliance with laws on seat belts and hand held mobile phones by drivers in London, and almost no effect of the end of the grace period on the use of a mobile phone while driving. Compliance with both laws should have improved in the second phase of observations if the public had perceived that scrutiny of drivers by police had intensified. Evidence from a small study in Birmingham indicated that use of mobile phones while driving had changed when the law on mobile phones was originally introduced, at the beginning of December 2003, but because the second phase of this study included February and March 2004, the impact of possible penalties was difficult to discern. ${ }^{16}$

We have no evidence that the use of seat belts improved, and we cannot approach the question indirectly by analysing longitudinal data on the pattern and severity of injuries to drivers involved in road crashes in London. Our observation that almost one in six drivers was not wearing a seat belt is a major public health concern.

The theory of risk compensation predicts that drivers of four wheel drive vehicles would take more risks when driving. Our findings that drivers of four wheel drive vehicles are more likely to use mobile phones and not to use seatbelts while driving strongly support this hypothesis.

\section{Limitations and strengths of our study}

Our findings that use of hand held mobile phones was higher in drivers of four wheel drive vehicles than drivers of normal cars are unlikely to be explained by differential ownership of mobile phones by people who can afford a four wheel drive vehicle. Mobile phones were so cheap by early 2004 that ability to pay for one is unlikely to explain a fourfold difference in their use while driving in London. Drivers of four wheel drive vehicles were also more likely to ignore laws on the use of seat belts, which suggests that they systematically ignored laws intended to improve safety on the roads. Another study has also reported that people who

Table 2 Factors associated with using a mobile phone and not using a seat belt while driving in London

\begin{tabular}{ll} 
Factor & Incidence rate ratio* $\mathbf{( 9 5 \%} \mathbf{C I})$ \\
\hline Using a mobile phone & \\
\hline Phase ("grace" or penalty) & $1.12(0.97$ to 1.29$)$ \\
\hline No seat belt & $1.47(1.27$ to 1.70$)$ \\
\hline Four wheel drive vehicle & 3.89 (3.36 to 4.49$)$ \\
\hline Density of traffic (greater than median) & 0.65 (0.57 to 0.75$)$ \\
\hline Not using a seat belt & \\
\hline Phase ("grace" or penalty) & $1.04(0.97$ to 1.13$)$ \\
\hline Using a mobile telephone & $1.37(1.20$ to 1.57$)$ \\
\hline Driving a four wheel drive vehicle & $1.26(1.16$ to 1.38$)$ \\
\hline Density of traffic (greater than median) & $0.76(0.71$ to 0.82$)$ \\
\hline
\end{tabular}

*Adjusted for time, day of the week, location, and driving conditions. 
use a mobile phone while driving are more likely not to use seat belts. ${ }^{17}$

The volume of traffic and the behaviour of drivers differed between the various sites and at different times and on different days of the week; volume of traffic and behaviour also varied slightly in different driving conditions. We adjusted for these potential confounding factors. The different periods and sites of observation and the large numbers of vehicles counted are strengths of our study. All data were collected by one person, eliminating interobserver variation as a source of error, but our study is potentially open to observer bias because the observer was not blinded to our hypothesis of risk compensation.

Some features of the design of four wheel drive vehicles, especially tinted windows, meant that we had more missing data for drivers of those vehicles than for drivers of normal cars. However, the proportion of missing data was small, and we probably did not introduce an artefact by omitting such vehicles from our analyses because having tinted windows, which relate to comfort and privacy, is unlikely to be related to behaviours concerned with safety. However, if we assume that all drivers for whom data were missing observed both relevant laws, the excess risk associated with four wheel drive vehicles is still significant. Thus, our main finding that drivers of four wheel drive vehicles are more likely than drivers of normal cars not to respect the law on use of mobile phones seems to be robust.

\section{Conclusion}

Our data provide no evidence that the end of the grace period on the use of hand held mobile phones had any effect on compliance with the new law in a large series of drivers in London. The extent of non-compliance may be even greater than we reported if whole journeys are taken into account. Noncompliance with regard to mobile phones was associated with failure to wear a seat belt while driving, the prevalence of which was high. Greater efforts are needed to educate the public and enforce these laws. Drivers of four wheel drive vehicles were more likely than drivers of cars to break both laws, consistent with the theory of risk compensation. Although four wheel drive vehicles are safer in a crash, their owners may be placing themselves and other road users at increased risk of injury.

Contributors: This study formed part of the honours degree of JW at Imperial College. All authors helped design the project. JW did all fieldwork, preliminary statistical analyses, and preparation of a detailed report that formed the basis of the manuscript. LW did further analyses and helped prepare the manuscript. KJ drafted the manuscript and is guarantor.Funding: None.

Conflicts of interest: None declared.

Ethical approval: Riverside research ethics committee.

1 Peltzman S. The effects of automobile safety regulation. J Polit Econ 1975;83:677-725. 2 Harvey AC, Durbin J. The effects of seat belt legislation on British road casualties: a case study in structural time series modelling. J R Stat Soc A 1986;149:187-227.

3 Adams J. Risk. 5th ed. London: UCL Press, 2000.
4 Toy EL, Hammitt JK. Safety impacts of SUVs, vans, and pickup trucks in two-vehicle crashes. Risk Anal 2003;23:641-50.

5 Broyles RW, Narine L, Clarke SR, Baker DR. Factors associated with the likelihood of injury resulting from collisions between four-wheel drive vehicles and passenger cars. Accident Anal Prev 2003;35:677-81.

6 McKnight AJ, McKnight AS. The effect of cellular phone use upon driver attention. Accident Anal Prev 1993;25:259-65.

7 Violanti JM, Marshall JR. Cellular phones and traffic accidents: an epidemiological approach. Accident Anal Prev 1996;28:265-70.

8 Violanti JM. Cellular phones and traffic accidents. Public Health 1997;111:423-8.

9 Lamble D, Kauranen T, Laakso M, Summala H. Cognitive load and detection thresholds in car following situations: safety implications for using mobile (cellular) telthresholds in car following situations: safety implications
ephones while driving. Accid Anal Prev 1999;31:617-23.

10 Stewart W. Mobile phones and health: the report of the Independent Expert Group on Mobile Stewart W. Mobile phones and health: the report of the Independent Expert Group on Mobile
Phones. Independent Expert Group on Mobile Phones, April 2000. www.iegmp.org.uk/ report/text.htm (last accessed 7 May 2004).

11 Royal Society for Prevention of Accidents. The risk of using a mobile phone whilst driving. Birmingham, UK: ROSPA. www.rospa.com/roadsafety/info/ mobile_phone_report.pdf (last accessed 7 May 2004).

12 Redelmeier DĀ, Tibshirani RJ. Association between cellular-telephone calls and motor vehicle collisions. N Engl J Med 1997;336:453-8.

13 Taylor DM, Bennett DM, Carter M, Garewal D. Mobile phone use amongst Melbourne drivers, a preventable exposure to injury risk. Med J Aust 2003;179:140-2.

14 McCartt AT, Braver ER, Geary LL. Drivers use of handheld mobile phones, before and McCartt AT, Braver ER, Geary LL. Drivers use of handheld mobile
after New York State's cell phone law. Prev Med 2003;36:629-35.

15 Rajalin S, Summula H, Poysti L, Anteroinen P, Porter BE. In-car cell phone use and hazards following hands free legislation. Traffic Inj Prev 2005;6:225-9.

16 Johal S, Napier F, Britt-Compton J, Marshall T. Mobile phones and driving. J Public Health 2005;27:112-3.

17 Eby JM, Vivoda JM. Driver hand-held mobile phone use and safety belt use. Accident Anal Prev 2003;35:893-5.

(Accepted 3 May 2006)

doi $10.1136 /$ bmj.38848.627731.2F

Department of Primary Care and Social Medicine, Imperial College, London Lesley Walker research associate

Jonathan Williams medical student

School of Population Health, University of Queensland, Herston, Qld 4006,

Australia

Konrad Jamrozik professor of evidence based health care

Correspondence to: K Jamrozik k.jamrozik@sph.uq.edu.au

\section{What is already known on this topic}

Using a hand held mobile telephone while driving is associated with a fourfold increase in the risk of having a road crash

It is now illegal to use a hand held mobile telephone while driving in the UK

\section{What this study adds}

Drivers of four wheel drive vehicles in London were four times more likely than drivers of other cars to use hand held mobile phones and slightly more likely not to comply with the law on seat belts

Levels of non-compliance with both laws were slightly higher in the second phase of observation, when the law on mobile telephones was fully enforced 